Article

\title{
Local Vegetation Trends in the Sahel of Mali and Senegal Using Long Time Series FAPAR Satellite Products and Field Measurement (1982-2010)
}

\author{
Martin Brandt ${ }^{1, *}$, Aleixandre Verger ${ }^{2,4}$, Abdoul Aziz Diouf ${ }^{3}$, Frédéric Baret ${ }^{4}$ \\ and Cyrus Samimi ${ }^{1,5}$ \\ ${ }^{1}$ Institute of Geography, University of Bayreuth, D-95440 Bayreuth , Germany; \\ E-Mail: cyrus.samimi@uni-bayreuth.de \\ ${ }^{2}$ CREAF, Cerdanyola del Vallès, E-08193 Catalonia, Spain; E-Mail: verger@creaf.uab.es \\ ${ }^{3}$ Centre de Suivi Ecologique, Dakar-Fann BP 13532, Senegal; E-Mail: dioufee@gmail.com \\ ${ }^{4}$ INRA-EMMAH, UMR 1114, Site Agroparc, F-84914 Avignon, France; \\ E-Mail: baret@avignon.inra.fr \\ ${ }^{5}$ BayCEER, University of Bayreuth, D-95440 Bayreuth, Germany \\ * Author to whom correspondence should be addressed; E-Mail: martin_brandt@gmx.net; \\ Tel: +49-1769-8269-998.
}

Received: 17 January 2014; in revised form: 27 February 2014 / Accepted: 3 March 2014 /

Published: 19 March 2014

\begin{abstract}
Local vegetation trends in the Sahel of Mali and Senegal from Geoland Version 1 (GEOV1) $(5 \mathrm{~km})$ and the third generation Global Inventory Modeling and Mapping Studies (GIMMS3g) $(8 \mathrm{~km}$ ) Fraction of Absorbed Photosynthetically Active Radiation (FAPAR) time series are studied over 29 years. For validation and interpretation of observed greenness trends, two methods are applied: (1) a qualitative approach using in-depth knowledge of the study areas and (2) a quantitative approach by time series of biomass observations and rainfall data. Significant greening trends from 1982 to 2010 are consistently observed in both GEOV1 and GIMMS3g FAPAR datasets. Annual rainfall increased significantly during the observed time period, explaining large parts of FAPAR variations at a regional scale. Locally, GEOV1 data reveals a heterogeneous pattern of vegetation change, which is confirmed by long-term ground data and site visits. The spatial variability in the observed vegetation trends in the Sahel area are mainly caused by varying tree- and land-cover, which are controlled by human impact, soil and drought resilience. A large proportion of the positive trends are caused by the increment in leaf biomass of woody species that has almost doubled since the 1980s due to a tree cover regeneration after a dry-period. This confirms the re-greening of the
\end{abstract}


Sahel, however, degradation is also present and sometimes obscured by greening. GEOV1 as compared to GIMMS3g made it possible to better characterize the spatial pattern of trends and identify the degraded areas in the study region.

Keywords: land degradation; greening; drought; Sahel; FAPAR time series; GIMMS3g; Geoland; biomass observations; Senegal; Mali

\section{Introduction}

The West African Sahel is an area that has experienced recent climatic and environmental changes (e.g., [1,2]). After severe droughts in the 1970s and 1980s, large areas were branded as degraded land (e.g., [3]). However, satellite time series starting in 1981 revealed a significant greening trend, which can only be partly explained by increasing rainfall [4]. Thus, a new re-greening debate largely replaced the previous degradation paradigm (e.g., [5,6]), although evidence of actual greening and increasing tree densities does not always correlate with greening trends derived from satellite time series [7]. Recently, Brandt et al. [8] and Herrmann \& Tappan [7] highlighted how diverse processes on a local scale can be, and that a positive vegetation trend does not necessarily mean an environmental improvement, as a remarkable species impoverishment was detected in both studies.

Time series analyses based on moderate and coarse resolution satellite data are widely used for monitoring vegetation. In regions with high intra- and inter-seasonal vegetation dynamics, mainly caused by rainfall variability, traditional change detection methods fail to succeed, making continuous data over a long time period irreplaceable. Remote sensing products have been tested against each other and found to be highly consistent for the entire Sahel $[9,10]$. Recent studies are scaled from global [11] to local [7] dimensions. Short term trends at a moderate scale $(250 \mathrm{~m}-1 \mathrm{~km})$ are studied with SPOT VEGETATION (VGT) (starting 1998) and Moderate Resolution Imaging Spectroradiometer (MODIS) (starting 2000) [12,13]. In Africa, continuous moderate resolution data of years prior to 1998 are only regionally available at $1.1 \mathrm{~km}$ from LAC (Local Area Coverage) AVHRR (Advanced Very High Resolution Radiometer) receiving stations [14-16]. However, poor quality, difficulties in data processing and availability hampers the use in the West African Sahel. Alternatively, the Normalized Difference Vegetation Index (NDVI) Global Inventory Modeling and Mapping Studies (GIMMS) time series starting in the year 1981 with $8 \mathrm{~km}$ spatial resolution derived from the AVHRR global GAC (Global Area Coverage) dataset [17] has been widely used for long-term trends [4,18-20]. The latest version, termed the third generation GIMMS3g dataset has been recently produced for the period July 1981 to December 2011 with AVHRR sensor data from NOAA (National Oceanic and Atmospheric Administration) 7-18 satellites with an improved calibration. In addition to the NDVI, Fraction of Absorbed Photosynthetically Active Radiation (FAPAR) and Leaf Area Index (LAI) products have been derived from GIMMS3g dataset to provide quantitative information of the state of earth's vegetation at $8 \mathrm{~km}$ resolution and 15-day intervals [21]. The recently delivered Geoland Version 1 (GEOV1) time series of FAPAR, LAI and Fraction of Vegetation Cover (FCOVER) based on AVHRR LTDR (Long Term Data Record) dataset combined with SPOT VGT offer a spatial resolution of approximately $5 \mathrm{~km}$ for the period 
1981-1998 and $1 \mathrm{~km}$ from 1999 to present [22,23]. Although the main problem of these long-term time series is their very coarse resolution, merging heterogeneous processes and characteristics on the ground into one single pixel, the higher spatial resolution of the GEOV1 dataset as compared to GIMMS3g may contribute to improve local trend analysis. In the Sahel, long term vegetation trend studies using GEOV1 have not been conducted so far. GIMMS3g is mostly used at a global scale [24-26] and studies are rarely located in the Sahel $[9,27]$.

Ground-truthing of vegetation trends in the Sahel can be extremely difficult, as landscapes and human activities are not uniform and even if the region is well known, (1) the actual causes of trends remain unclear and (2) degradation or greening can be obscured or neutralized by mixed spectral information from changes of adjacent objects. So far, ground-truthing has rarely been linked to long-term trend studies in the Sahel. Only few studies go beyond hypothetical interpretations of the trends. Herrmann \& Tappan [7] use botanic inventory sites over 27 years, while Brandt et al. [8] present an interdisciplinary and descriptive approach. Bégué et al. [18] related greening trends to land-cover changes, finding some correlations in the Sahel. Dardel et al. [9] compared long-term field observations with GIMMS3g NDVI data, finding a good consistency of positive vegetation trends in Mali $\left(\mathrm{R}^{2}=0.59\right)$ and negative trends in Niger $\left(\mathrm{R}^{2}=0.38\right)$.

This study uses FAPAR time series instead of NDVI. FAPAR is defined as the fraction of radiation absorbed by the canopy in the 400-700 nm spectral domain under specified illumination conditions [28]. It is directly related to the photosynthesis and it is used as an input in light use efficiency models. The relationship between NDVI and FAPAR has been found to be linear for green vegetation, particularly in the semi-arid environment of the Sahel. A number of satellite-related (including atmospheric effects and view-sun angle geometry) and canopy-related (including leaf angle distribution, canopy heterogeneity, brown elements and soil color) factors are found to influence the parameters of this linear relation which is site-specific and often only valid when calibrated for a given soil type [13]. Compared with NDVI, the FAPAR satellite products mitigate the impact of soil background for low vegetated canopies and the saturation effects for high vegetation amount [29].

The purpose of this study is to assess local vegetation trends in the Sahel of Mali and Senegal in the period 1982-2010 by combining long-term FAPAR satellite datasets with ground based data. The potential of GEOV1 and GIMMS3g time series for trend detection is assessed and validated with biomass observations, rainfall data and site visits. This study is designed to better understand the processes responsible for satellite derived trends and, thus, to shed more light on the re-greening debate of the Sahel area.

\section{Materials and Methods}

Our study uses coarse scale GEOV1 and GIMMS3g FAPAR satellite time series to examine local vegetation trend patterns in two Sahelian study areas. Validation and interpretation of the spatial pattern and magnitude of observed vegetation trends is based on two methodologies: (1) a qualitative approach using in-depth knowledge of the regions and (2) a quantitative approach through the comparison with biomass field measurements and rainfall data. 


\subsection{Study Areas}

The study areas are located in the Sahel of Mali and Senegal, an area with evidence of significant environmental changes over the studied time period. Greening and degradation have both been observed in the study areas, offering a heterogeneous pattern of vegetation change [2,8,30,31]. Human impact, morpho-pedology as well as rainfall variability have shaped a diversified landscape. Six test sites with oppositional land-cover trends were chosen for further analysis (MALdeg, MALpos, C3L5, C2L5, C2L4, Ldeg, shown in Table 1 and illustrated in Figure 1). The two study areas and the location of the six test sites are shown in Figure 2.

Table 1. Location and site characteristics for the Sahelian test sites presented in this study.

\begin{tabular}{|c|c|c|c|}
\hline Sites & Location & Coordinates (Long./Lat.) & Site Characteristics \\
\hline MALdeg & $\begin{array}{l}\text { Mali, Dogon } \\
\text { Plateau }\end{array}$ & -3.873814 .4276 & $\begin{array}{l}\text { Tree-, shrub savanna, degraded bushland, } \\
\text { crops, ferruginous, shallow soils }\end{array}$ \\
\hline MALpos & $\begin{array}{l}\text { Mali, Dogon } \\
\text { Plateau }\end{array}$ & -3.531214 .3253 & $\begin{array}{l}\text { Tree-, shrub savanna, cropping and onion } \\
\text { plantations line the valleys, dams and } \\
\text { irrigation structures }\end{array}$ \\
\hline$C 3 L 5$ & $\begin{array}{l}\text { Senegal, } \\
\text { ferruginous Ferlo }\end{array}$ & -14.581515 .2463 & $\begin{array}{l}\text { Shrub-, tree savanna, dense bushland, ferruginous, } \\
\text { spots of bare soil, shallow soils, pasture }\end{array}$ \\
\hline$C 2 L 5$ & $\begin{array}{l}\text { Senegal, } \\
\text { southern sandy } \\
\text { Ferlo }\end{array}$ & -15.203215 .2309 & $\begin{array}{l}\text { Tree-, shrub savanna, sandy, intersected by } \\
\text { clayey depressions, pasture and small scale croppin }\end{array}$ \\
\hline$C 2 L 4$ & $\begin{array}{l}\text { Senegal. } \\
\text { northern Ferlo }\end{array}$ & -15.285715 .6035 & $\begin{array}{l}\text { Open tree-, shrub savanna, sandy, pasture and } \\
\text { small scale cropping, fallow fields }\end{array}$ \\
\hline Ldeg & $\begin{array}{l}\text { Senegal, } \\
\text { ferruginous } \\
\text { Ferlo }\end{array}$ & -14.944415 .4718 & $\begin{array}{l}\text { Tree-, shrub savanna, ferruginous, laterite, } \\
\text { shallow soils, degraded, intersected with } \\
\text { woody depressions }\end{array}$ \\
\hline
\end{tabular}

\subsubsection{Bandiagara (Sahel of Mali)}

In Mali, the focus is on the Dogon Plateau around Bandiagara, east of Mopti. Around 10\% of the rocky and ferruginous plateau are not suitable for agriculture, while most of the remaining portion is used for rainfed cropping by Dogon farmers and livestock herding by Fulani pastoralists. In the past 50 years, droughts and human expansion have caused a considerable loss of natural woody vegetation, resulting in degraded land and an increase of cultivated areas [31]. Prevailing woody species are Balanites aegyptiaca, Combretum glutinosum, Guiera senegalensis, and especially on fields Faidherbia albida. The plateau is represented by two case study sites (see Figure 1, [32] and Table 1): large portions of the area around MALdeg are highly degraded with exposed laterite and only scattered spots of grass and woody vegetation remaining (Figure 1a). On the contrary, MALpos represents an area with large scale onion plantations and fertile fields (Figure 1b), surrounded by a dense shrubby vegetation on rocks. 
Figure 1. Study sites in Mali (a,b) and Senegal (c-f); illustrated by RapidEye images [32] (bands 532, December 2010) and photos, taken in December 2011 (a,b); March 2012 (d) and September 2012 (c,e,f). Site (a) is located on the lateritic Dogon Plateau with small spots of bushland left, visible as red spots in RapidEye. Degradation (dark color) fills up most parts of the image. Onion plantations (bright red) are present at (b) and stay green into the dry season due to irrigation. The rocky surroundings are covered by Combretum micranthum shrubs. Site (c) illustrates the ferruginous Ferlo with a dense shrubby vegetation dominated by Pterocarpus lucens, Guiera senegalensis and Boscia senegalensis but also unvegetated spots; (d) represents the southern sandy Ferlo, intersected by forested depressions. Sclerocarya birrea and Balanites aegyptiaca are seen on the dry season photo; Site (e) is located in the northern sandy Ferlo with an open tree and shrub savanna. Small Combretum glutinosum and Balanites aegyptiaca, severely cut by humans can be seen on the photo; Site (f) reveals different details in different resolutions: while the GIMMS pixel (blue grid) mixes the degraded area with peanut-fields further north, the GEOV1 (red grid) pixel captures the largely degraded area.

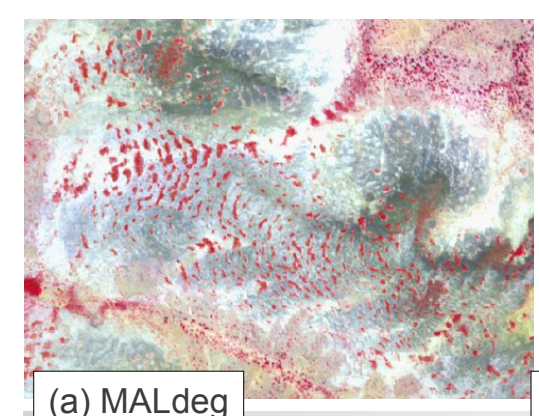

(a) MALdeg
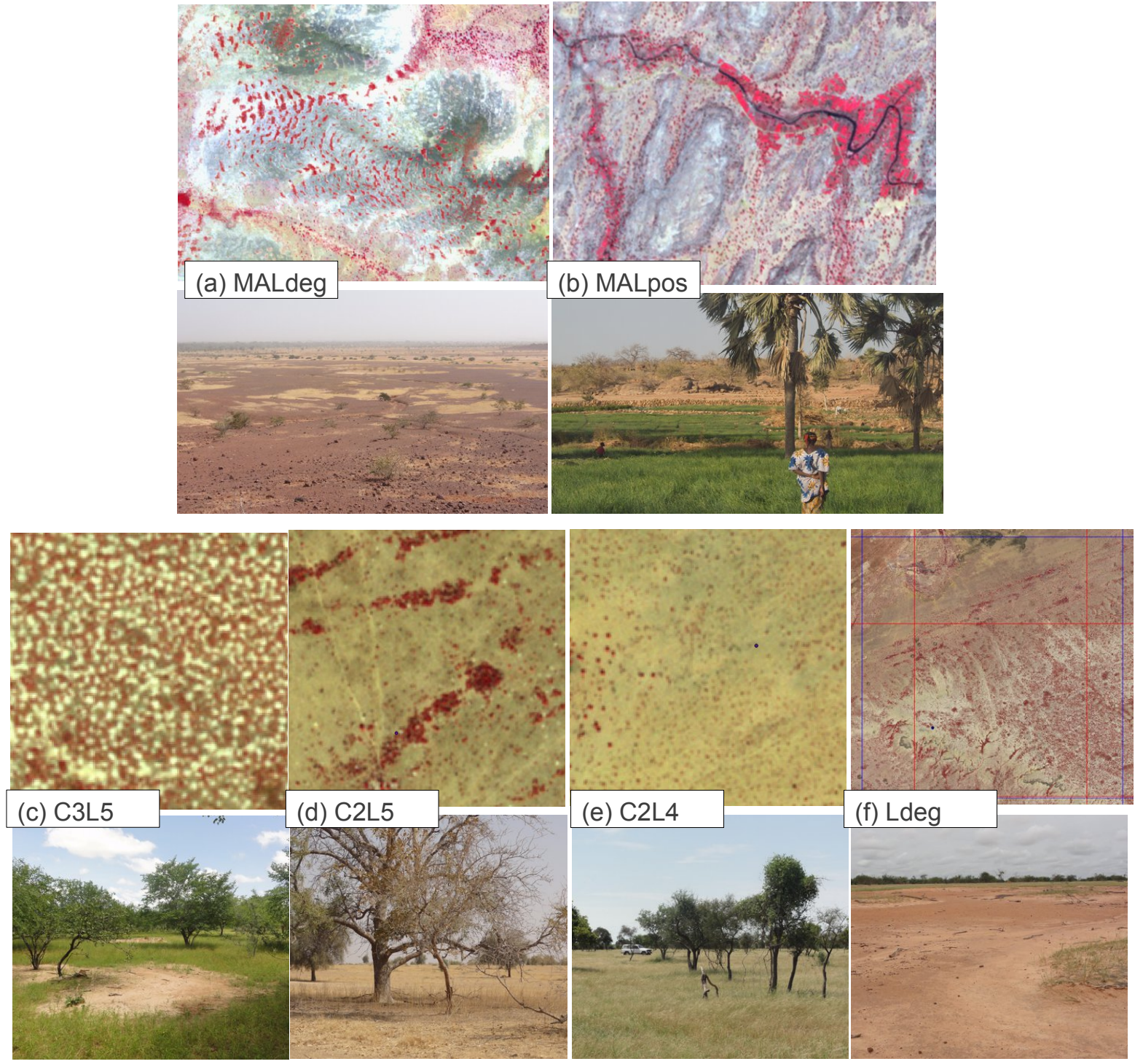
Figure 2. Accumulated FAPAR for mean rainy season (August-October) of GEOV1 FAPAR (left) and GIMMS3g FAPAR (right) from 1982 to 2010. Banidgara (a,b) and Linguère (c,d) regions both show a good agreement between the two datasets with more details in GEOV1. Sandy areas can be distinguished from lateritic sections (Dogon Plateau in Mali and ferruginous Ferlo in Senegal). In Mali, the Bandiagara escarpment separates the Dogon Plateau from the Seno Plain around Bankass. All rasters were interpolated to a spatial resolution of $1 \mathrm{~km}$ by a bicubic interpolation method for a better visual inspection and interpretation. No quantitative information is lost nor added by applying this method.
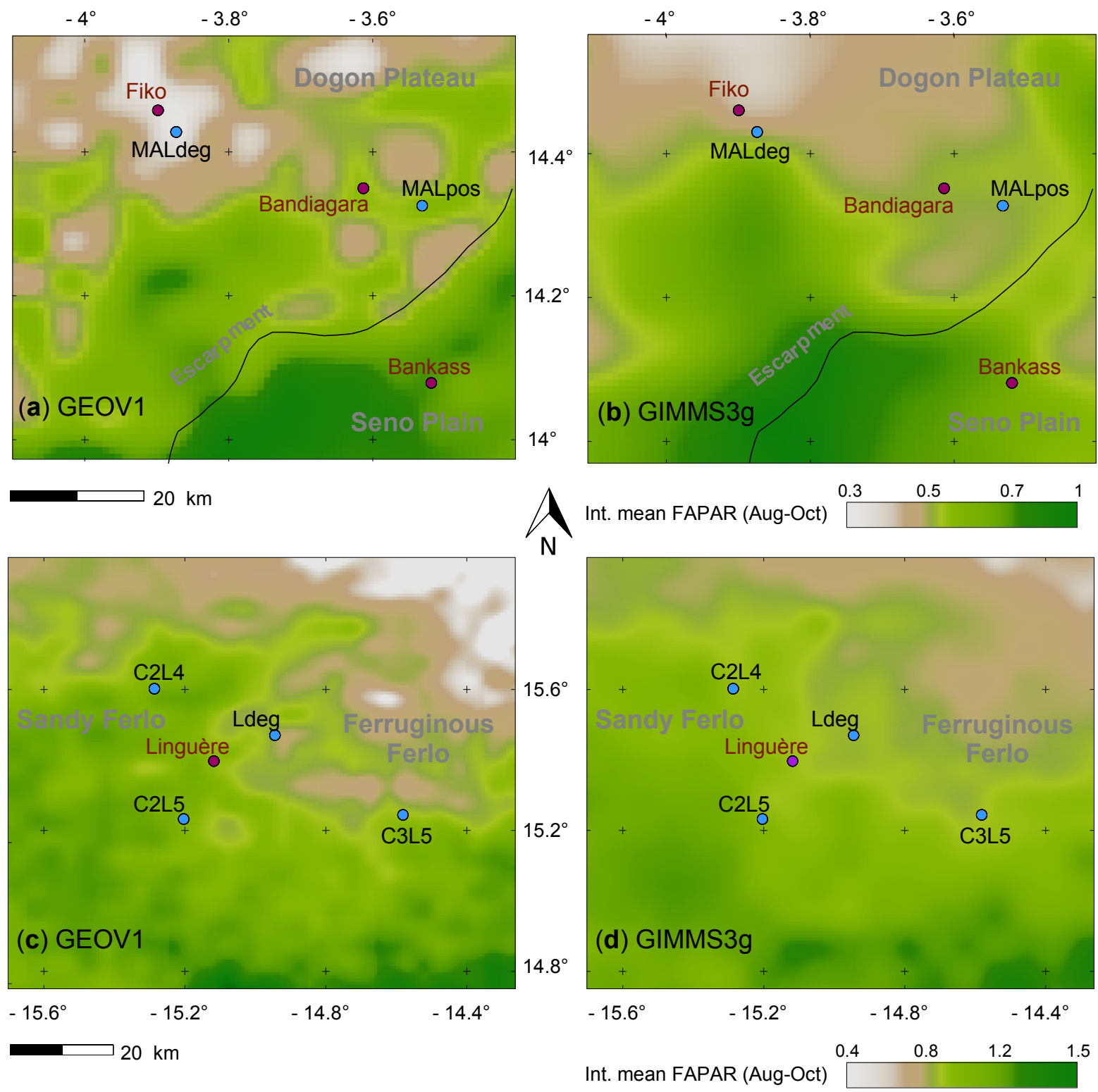

South-east of the Bandiagara escarpment, the Seno Plain represents a different morphological zone (Figure 2). In the absence of rocks and laterite, Dogon and Fulani farmers cultivate almost $90 \%$ of its deep sandy soils. In 1967, about $40 \%$ were still covered by dense bushland, which was cleared due to human expansion and the need for cropping land [31]. 


\subsubsection{Linguère (Sahel of Senegal)}

The Ferlo region around the Senegalese city Linguère forms our second study area. The ferruginous part lies east of Linguère and was severely affected by droughts in the 1970s and 1980s with a remarkable reduction of tree density [2]. Especially in the past 10 years, the vegetation has been recovering with increasing rainfall, but deforestation and degradation are also apparent, mainly along ancient valleys and in proximity to wells and villages [8]. The region has shallow and unfertile soils with laterite exposed at many sites. It belongs to the silvo-pastoral zone and therefore agriculture and settlements are rare in the whole area, which is used by Fulani herders for livestock grazing. Much of the dense bushland has never been cleared and woody vegetation is a shrub and tree savanna with Pterocarpus lucens, Guiera senegalensis and Boscia senegalensis prevailing. Test sites C3L5 and Ldeg both lie within this area, representing oppositional stages of degradation. While $C 3 L 5$ consists of a relatively dense woody vegetation (Figure 1c), Ldeg is seriously degraded (Figure 1f). As most of the trees were felled or died during droughts, soil erosion caused a loss of upper soil and remaining vegetation can only be found in small clayey depressions.

The sandy Ferlo west, south and north of Linguère is infrequently used for cropping and strongly influenced by human activities. It consists of sandy fossil dune soils, of which approximately $15 \%$ are cultivated by Wolof farmers. Most of the bushland has been cleared in the 20th century and the current woody vegetation is an open tree and shrub savanna dominated by Balanites aegyptiaca, Acacia raddiana and Combretum glutinosum. Drought resilience of these species growing on sandy soils is good, thus overall tree mortality was moderate during the dry period (1970s-1990s). Test sites C2L5 and C2LA are both situated within this area. South of Linguère, C2L5 represents the southern part of the sandy Ferlo, which is dissected with clayey and forested depressions and mainly used for pasture purposes and small scale cropping (Figure 1c, Table 1). C2L4 is located north of Linguère. Parts of the region used to be cultivated but recently lie fallow due to a lack of rain. Trees and shrubs in this area are severely affected by human impact (Figure 1d, Table 1).

\subsection{FAPAR Time Series}

Global GEOV1 FAPAR time series derived from AVHRR LTDR (1981-2000) and from VGT (1999-present) data have been recently delivered within the Geoland2 project. Products are freely available at 10-day time intervals and approximately $5 \mathrm{~km}(1 \mathrm{~km})$ for AVHRR (VGT). The GEOV1 VGT FAPAR product is based on a combination of already existing products to take advantage of their specific performances while limiting the situations where products show deficiencies. In line with the published literature on products validation, the MODIS and CYCLOPES [28] products are selected since they provide higher level of consistency [33]. The selected products are combined and eventually scaled to compute the fused product that is expected to provide the best performances globally. Neural networks are then calibrated to relate the fused products to the corresponding VGT L3a top of canopy directionally normalized reflectances [34]. The GEOV1 AVHRR algorithm aims to ensure robustness and consistency of the derived FAPAR product with GEOV1 VGT. The approach is based on the use of neural networks to mimic the GEOV1 VGT product using AVHRR LTDR reflectances and dedicated temporal smoothing 
and gap filing techniques to improve the consistency and continuity of the derived time series. Further information are available in Baret et al. [22] and Verger et al. [23].

Similarly as in GEOV1, the principles used for the generation of GIMMS3g FAPAR are based on the use of neural networks to mimic an existing product, in this case, the MODIS FAPAR [21,34]. A neural network algorithm is first trained using both the NDVI GIMMS3g and MODIS FAPAR products over the overlapping period 2000-2009. The trained neural network algorithm is then applied using the land-cover class, pixel-center latitude, pixel-center longitude, and NDVI3g as inputs to generate time series of FAPAR from July 1981 to December 2011 at 15-day temporal steps and 1/12 degree (about $8 \mathrm{~km}$ ) spatial resolution over the globe. For further information, we refer to Zhu et al. [21].

For this study, monthly MVCs (Maximum Value Composites) were produced for both FAPAR datasets to derive temporally identical time series and to further eliminate contamination by clouds and atmospheric disturbances. With the assumption that exceptional low values are contaminated, the highest value of each month was selected. Figure 2 presents the accumulated GEOV1 FAPAR and GIMMS3g FAPAR over the period 1982 to 2010 for the mean rainy season (August-October) in the Bandiagara and Linguère regions. Here, the spatial pattern and range of values for both products show a good agreement for both study areas. Ferruginous zones (Dogon Plateau in Mali and ferruginous Ferlo in Senegal, see Figure 2) can be distinguished from sandy zones, which are more productive and thus have a higher FAPAR. GEOV1 reveals more details and illustrates more spatial heterogeneity within these zones.

\subsection{Time Series Analysis}

Prior to the trend analysis, a pixel-wise Durbin-Watson test was carried out, which revealed significant autocorrelation in the monthly time series of both FAPAR datasets (values between 0.5 and 0.8 $(p \leq 0.05))$. Therefore, in order to correct for autocorrelation and to filter out remaining noise, we applied a Seasonal Trend decomposition based on Loess (STL) to the monthly MVCs [35]. Here, a local regression was used to decompose a times series into seasonal, yearly and noise components. For every pixel and each year, the yearly component was extracted and further processed. Using the de-noised yearly component has the additional advantage that singular seasonal effects are not overestimated and adds focus on the evergreen woody layer [36]. This produces trends that are more significant and detects subtle gradual changes. A linear regression was applied for each pixel to the preprocessed datasets with the yearly components for the period 1982-2010. The slope of the yearly components was derived to quantify the direction and magnitude of the overall trend. Slope values were recalculated to FAPAR units by multiplication with the number of years to express the total change over time. Only pixels with a confidence level of $95 \%(p \leq 0.05)$ were further processed.

For reasons of comparability and to avoid unit inconsistencies, annual anomalies in percent were calculated for rainfall, integrated FAPAR and biomass data for the period 1987 to 2010 by dividing each individual year through the long-term mean. Here, annually integrated FAPAR is used instead of decomposed components to obtain comparable results with previous studies [37]. 


\subsection{Validation and Interpretation Data and Methods}

\subsubsection{Qualitative Information}

Fieldwork was conducted during the dry seasons 2011 and 2012 (February-April) and the rainy season 2012 (September, October). In close collaboration with local scholars, several natural scientists visited the two study areas and collected qualitative and quantitative information on woody coverage and species composition [38], soil erosion and degradation processes [39] as well as impact of humans and livestock on soil and vegetation. In addition, several social scientists conducted interviews in nearby villages to gather information on people's perception on the local climate, environment in general, woody cover and species, crop yields and capacities of pasture. Local people were questioned regarding recent conditions as well as environmental change over the past 30 and 50 years. Within the present study, this qualitative information strengthened the knowledge about the study areas and offered explanations on the causative factors for vegetation trends. More details on interview techniques and the applied field-methods can be found in Brandt et al. [8].

\subsubsection{Quantitative Information}

Biomass Observations

In the Bandiagara region, no long-term field data is available but the Gourma region further north has been the object of detailed studies. Dardel et al. [9] have shown that a good correlation between GIMMS3g NDVI time series and 27 years of field observations is present in Gourma $\left(\mathrm{R}^{2}=0.57\right)$. The CSE (Centre de Suivi Ecologique) collects biomass data throughout Senegal each year at the end of the rainy season at 36 sites, although only three are located in our study area $(C 3 L 5, C 2 L 5$ and C2L4). Most of the sites date back to 1987, representing areas of relatively homogeneous vegetation and soil. Trees, shrubs as well as the herbaceous layer were surveyed with a stratified sampling method based on transects and quadrats in an area of about $3 \times 3 \mathrm{~km}$ to calculate green biomass in $\mathrm{kg} \mathrm{DM}$ (Dry Matter)/ha for the woody and herbaceous layer separately. The stratification for the herbaceous production was based on the estimated production level of a vegetation type. Depending on the heterogeneity, up to 50 samples along a $1 \mathrm{~km}$ transect were collected. In a second step, $200 \mathrm{~g}$ samples were collected for each production level of green biomass and dried in an oven. The leaf production of trees was calculated using four quadrats of up to 1 ha which were placed along the line transect. Within the quadrats, trees were surveyed and woody production estimated by allometric relationships relating trunk circumference with typical production values of the species. Leaf production variations of individuals were calibrated by the ratio of leaf dry-weight of branches divided by standard branch values. After drying of samples and calculation of dry matter (herbaceous and leaves), the biomass production was estimated and extrapolated using a linear regression equation between dry matter samples and integrated NDVI (SPOT VGT). For information on data collection and biomass calculation methodologies, we refer to Diouf \& Lambin [37] and Diallo et al. [40].

Although the comparison of field measured above-ground biomass with remotely sensed greenness indexes (e.g., NDVI or FAPAR) is not trivial, several studies agree that a strong relationship exists. Fensholt et al. [41] compared 13 of the CSE sites throughout Senegal with integrated MODIS MOD15 
FAPAR for the year 2001, finding a good consistency $\left(\mathrm{R}^{2}=0.72\right)$. Diouf \& Lambin [37] correlated integrated NDVI from a local AVHRR receiving station with 12 CSE biomass monitoring sites between 1987 and 1997. They conclude that a strong relationship exists $\left(\mathrm{R}^{2}=0.68\right.$ in average), however, with large inter-annual variations, making NDVI a reasonable but not a robust proxy for biomass estimation in the Senegalese Sahel. Mbow et al. [42] discovered that species composition has a significant effect on the relationship between NDVI and biomass at a test site near Dahra, west of Linguère. The spatial unit size differences between ground sample areas and AVHRR pixels constitutes another source of error. The scope of this study is not a 1:1 comparison but to find investigate if (1) the direction; (2) the magnitude and (3) spatial discrepancies of long-term FAPAR trends correspond with ground data.

Figure 3. GPCC annual rainfall anomalies in percent for the period 1940-2010 averaged over the study areas of (a) Mali and (b) Senegal. Linguère weather-station data is included in (b), indicating that gridded GPCC data corresponds well with ground-measured station data (grey columns). Note the extraordinary dry period in the 1970s and 1980s. Data after Schneider et al. [45].

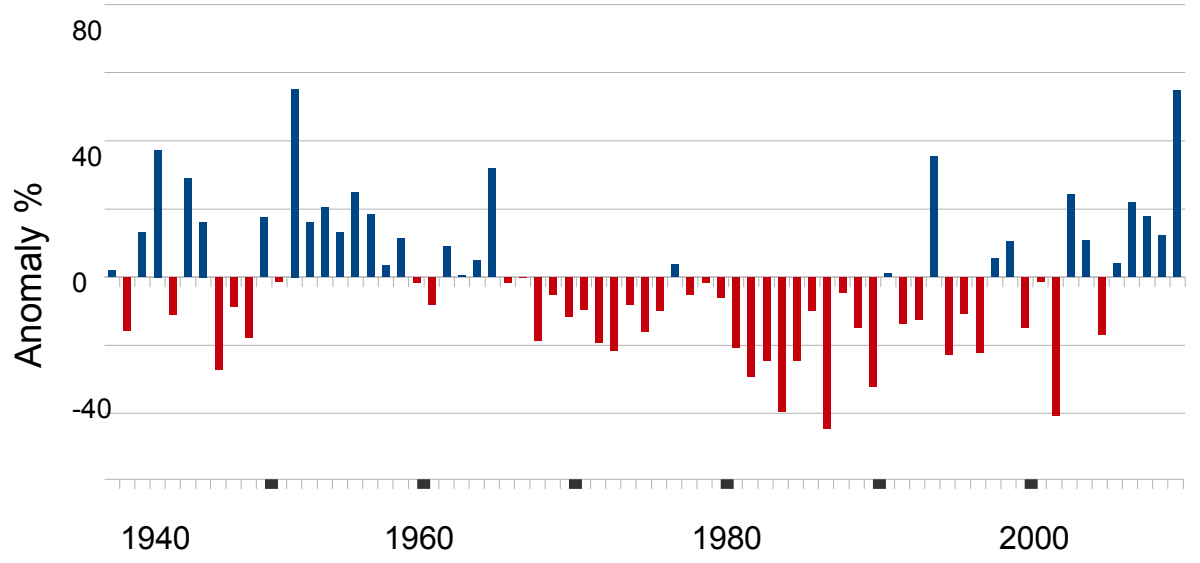

(a)

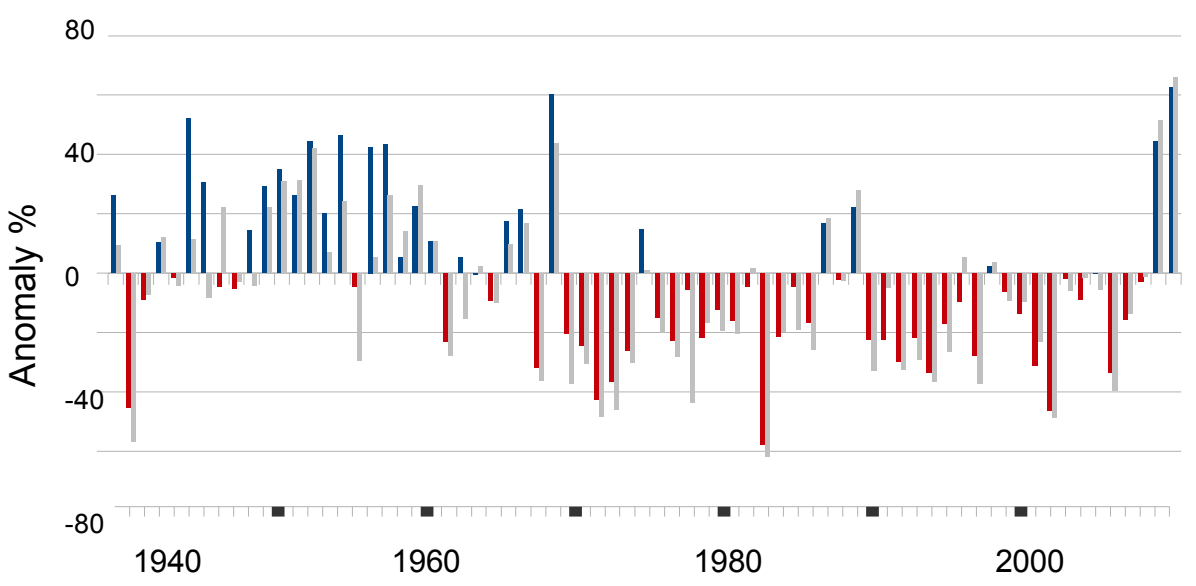

(b) 


\section{Rainfall Data}

In the Sahel, annual vegetation fluctuations are largely controlled by precipitation [43]. To better interpret the detected trends in FAPAR, rainfall data from local meteorological stations and from the Global Precipitation Climatology Centre (GPCC) dataset was included. The data is available for the Linguère weather station since 1933 [44] and since 1901 at a $0.5^{\circ}$ grid from the GPCC precipitation database v6. The $0.5^{\circ}$ grids are created by interpolating station data over approximately 90.000 weather stations globally [45]. GPCC data is consistent with local station data (see Figure 3b) and thus suited for further analysis. The two considered regions around Bandiagara in Mali (Figure 3a) and Linguère in Senegal (Figure 3b) have considerable intra- and inter-seasonal rainfall variability with almost the entire annual rainfall falling between June and October. After a wet period in the 1950s and 1960s, rainfall dropped far below average in both study areas from the 1970s to the 1990s. Since then, annual precipitation is increasing again, in Bandiagara more rapidly than in Linguère. Recently, mean annual rainfall lies around $430 \mathrm{~mm}$ in Linguère and $550 \mathrm{~mm}$ in Bandiagara.

\section{Results}

We first present results of FAPAR trend analysis on a continental level showing vegetation change for Western Africa. We then move on to a regional level choosing two Sahelian study areas, one around Bandiagara (Mali) and one around Linguère (Senegal). The trend patterns in the study areas are examined by means of six local case study sites and supported by qualitative and quantitative ground data.

\subsection{Trend Analysis of Western Africa}

Figure 4 illustrates significant FAPAR change for Western Africa using the GEOV1 product. Especially in the south, large areas remain insignificant due to permanent clouds in the VGT data, while the processing of AVHRR proves to be more stable here [23]. Large parts of the Sahel and Western Africa reveal significant positive change (about 65\%), confirming the re-greening hypothesis [9], but also negative change is detected (about 1\%). Negative change mostly correspond to large areas of deforestation, vegetation loss and land-cover change, especially in Nigeria, Togo and Ghana [46,47]. FAO statistics detect an annual deforestation rate of up to $4 \%$ between 1990 and 2010 in these countries [47], providing a possible explanation for the negative change. On the other hand, a positive change does not necessarily mean an increase in forest-cover but in biomass, which crops and grass can also cause. In 12 of 14 countries, forest-cover is decreasing, whereas most of them have a positive trend within the same time frame $[46,47]$. For a better understanding of the processes behind changes, it is inevitable to break down the scale to a local level. 
Figure 4. GEOV1 FAPAR change map of Western Africa (1982-2010). The map shows the slope of a linear regression with monthly MVCs multiplied by their number. Study areas are located around Linguère and Bandiagara.

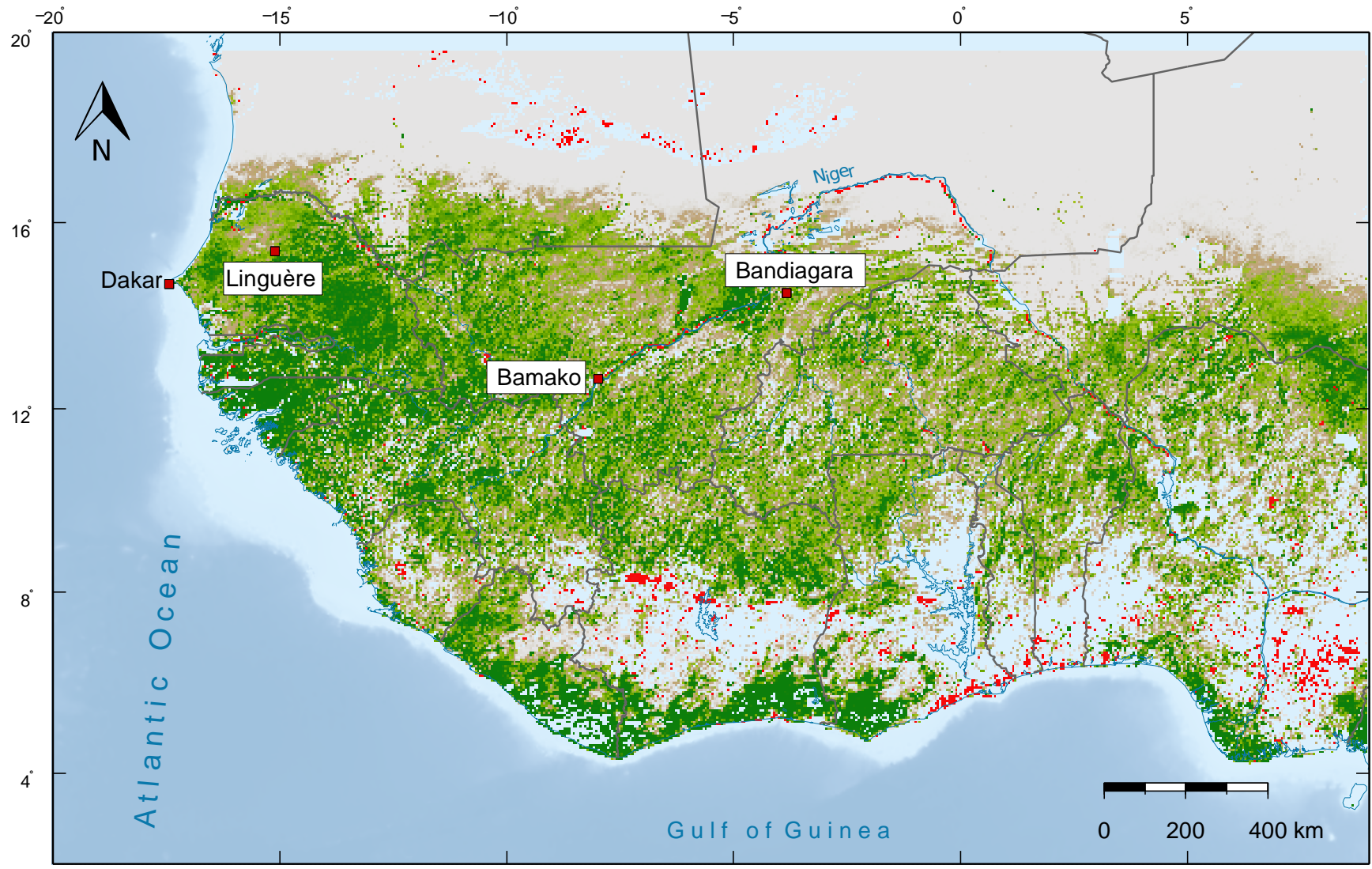

$\begin{array}{lllll}-0.3 & 0 & 0.15 & 0.3 & \text { not significant }(95 \%)\end{array}$

\subsection{Local Trend Patterns}

\subsubsection{Bandiagara (Sahel of Mali)}

Corresponding to increasing rainfall (Figure 3a), the Malian study area has a general positive greenness trend with major spatial discrepancies seen in Figure 5a,b. The magnitude and spatial distribution of changes differ between the two FAPAR data products. However, both GIMMS3g and GEOV1 FAPAR agree that (1) stronger positive areas are present on the Dogon Plateau around Bandiagara (Figure 5a,b); and (2) neutral or slightly positive trends indicating less productive areas are located in a large area south of Fiko (marked with MALdeg in Figure 5a,b). Around MALdeg, most parts of the formerly dense tiger-bush were cleared by human expansions and the need for cropping land in the 1960s but abandoned few decades later becoming bush-fallows again [30]. Beyond the currently active fields, bush-fallows are used for tree cutting with and without permits. This increased in times of drought and little rainfall, as selling trees is an established compensation for harvest losses. In combination with droughts, dry periods, floods and large livestock numbers, MALdeg has turned into a desert-like vast-land (see Figure 1a), which is recognized in the trend maps but spatially overestimated in GIMMS3g 
(Figure 5a,b). The temporal profiles of MALdeg in Figure 6a provide evidence of the low productivity and demonstrate that the degradation process began prior to the start of the time series (1982). However, degradation is still active, as FAPAR has decreased in the past decade, despite increasing precipitation (Figure 3a).

Figure 5. FAPAR change in the Bandiagara $(\mathbf{a}, \mathbf{b})$ and Linguère $(\mathbf{c}, \mathbf{d})$ region from 1982 to 2010 as evaluated with the GEOV1 FAPAR product (left), as well with the GIMMS3g FAPAR product (right). Trends were derived using the STL method and reveal a very heterogeneous pattern. The important differences in the magnitude of change for GIMMS3g and GEOV1 prevents the use of the same color bar. Lateritic areas show a much higher change than sandy ones in both study areas and degraded and deforested spots can be identified in GEOV1 change maps. Those spots are merged in GIMMS3g.
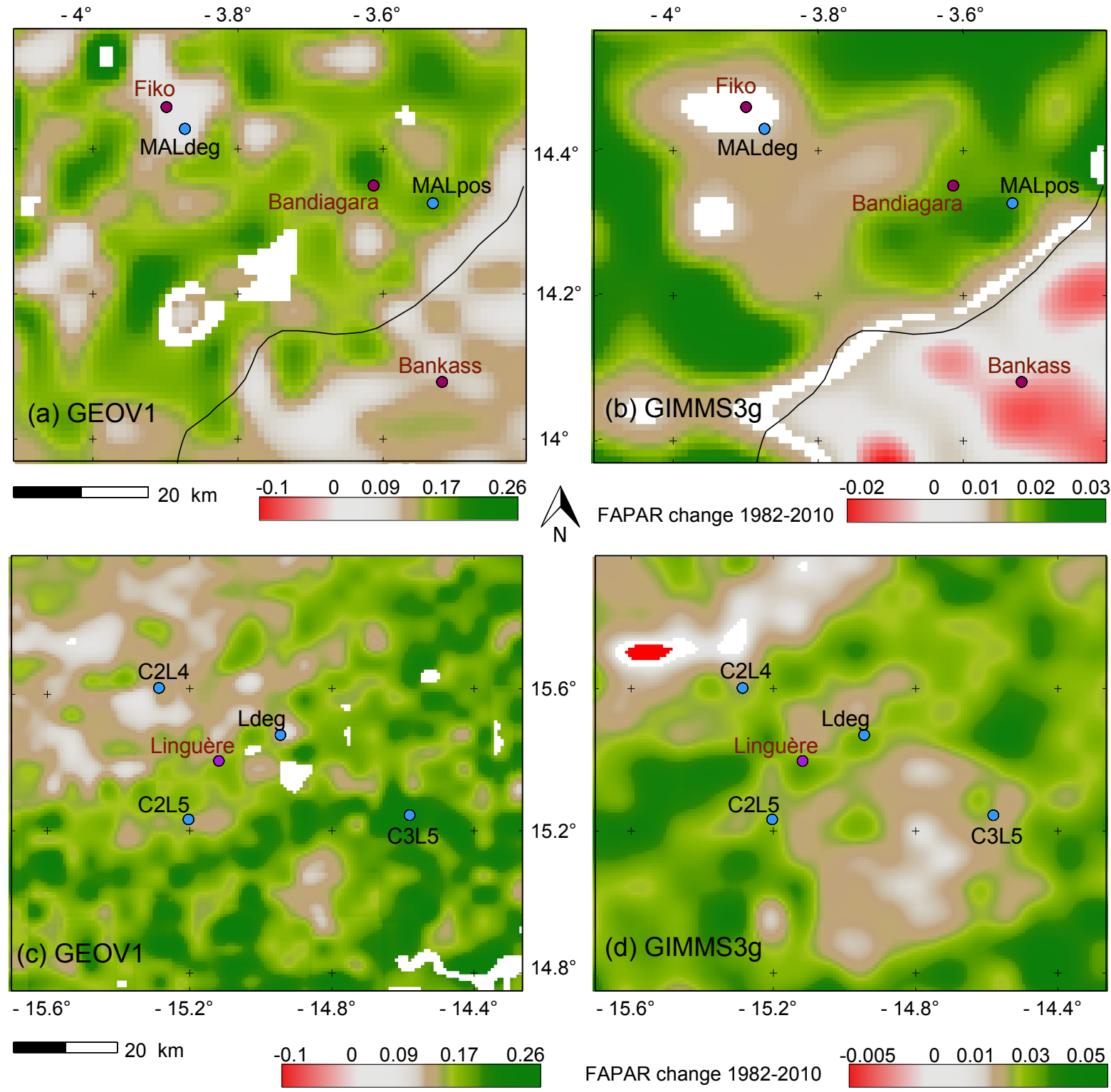
Figure 6. Temporal profiles extracted from the pixel overlaying two sites near Bandiagara (a,b) and four sites around Linguère (c-f) from 1982 to 2010. The numbers (top left) indicate change in FAPAR units. Profiles (a) show a large degraded area, which is the reason for a very small positive trend in GEOV1 and insignificy in GIMMS3g, despite of increasing rainfall; Profiles (b) are extracted over onion plantations, which were established after the year 2000 and therefore a strong positive trend can be observed in GEOV1. Site C3L5 (c) reacts to rainfall changes and therefore had a strong positive trend in the past decade. Drought years (especially $1983 \& 1984$ ) and the related damage on vegetation are clearly visible. The open tree savannas $(\mathrm{d}, \mathrm{e})$ have a moderate positive trend. Drought years are tempered better than in all profiles with lateritic soils. Temporal profiles (f) show a largely deforested and degraded area with a slightly positive trend.

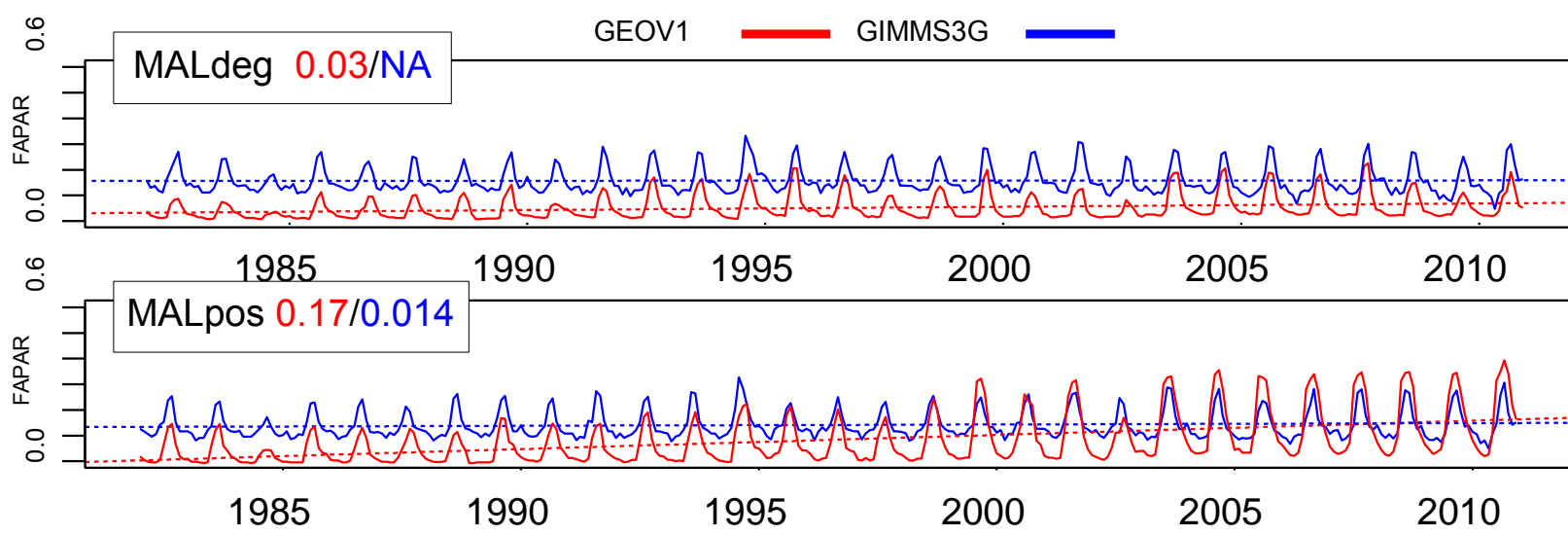

(a)
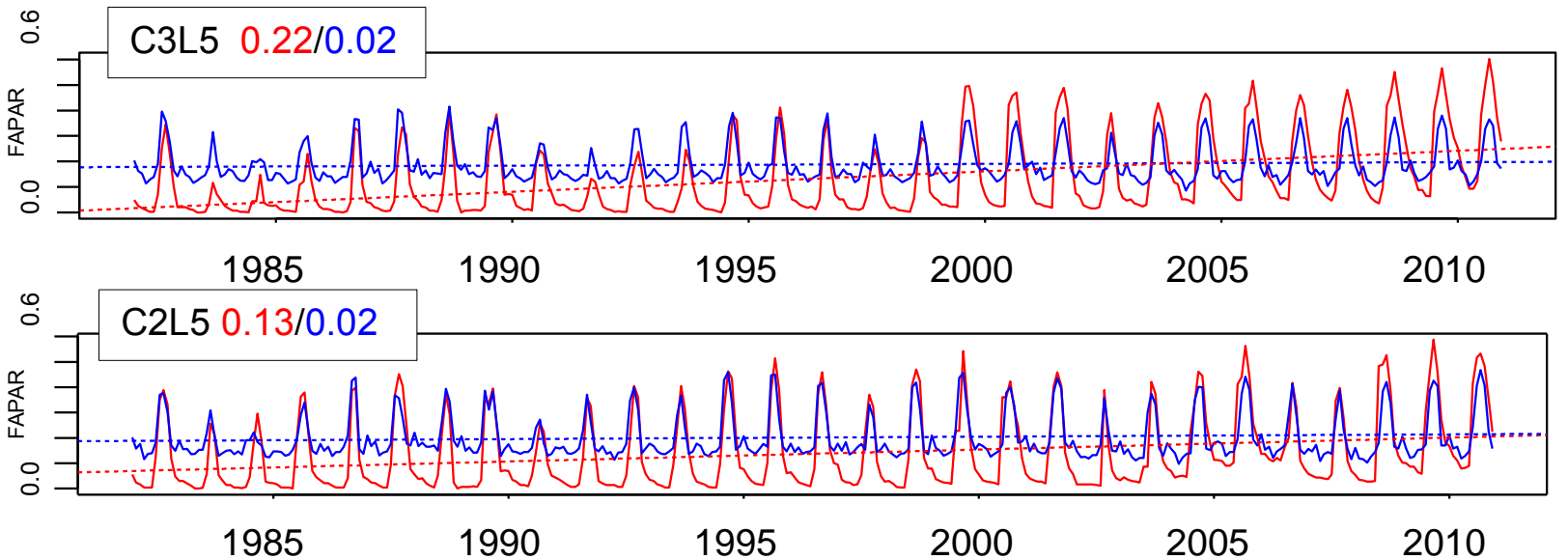

(d)

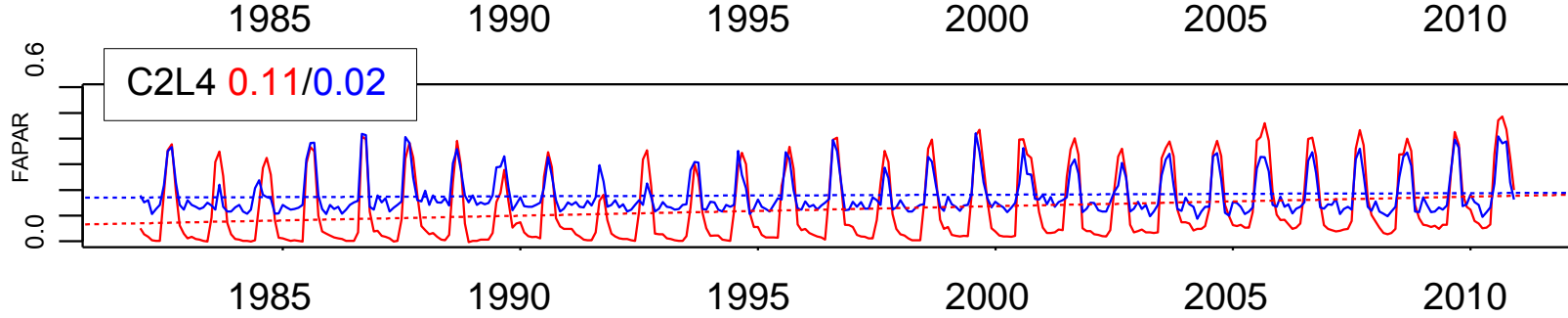

(e)

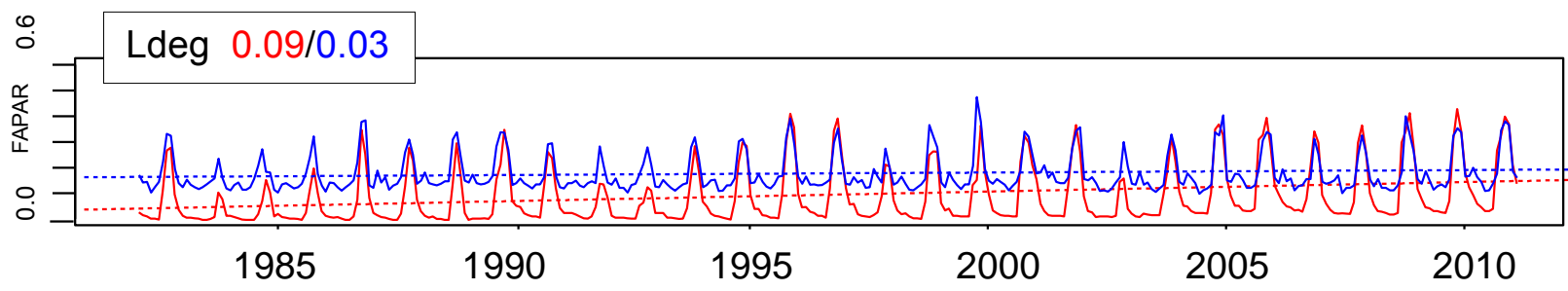

(f) 
As an example of positive change on the plateau, an area east of Bandiagara was chosen. Onion plantations were established around MALpos after the year 2000 (see Figures $1 \mathrm{~b}$ and $6 \mathrm{~b}$ ). These fields stay green long into the dry season due to irrigation. Cultivation activities in combination with drought-regeneration of semi-natural bushland, agro-forestry on fields, reforestation and tree protection laws, strongly influence the overlaying FAPAR pixels causing positive changes and prevailing greening areas on the entire Dogon Plateau. However, a share of almost $10 \%$ are deforested and seriously degraded [31], not following the greening trend. GEOV1 (Figure 4a) reveals more spatial discrepancies and details than GIMMS3g FAPAR, showing a variety of adjacent degraded and greening areas northeast of the escarpment (Figure 5a). According to the prevailing trend, those heterogeneous areas are merged in GIMMS3g to large areas of greening, irrespective of the degradation (Figure 5b).

On the Seno Plain around Bankass, droughts caused less damage to the woody vegetation on deep sandy soils as compared to the rocky plateau around Bandiagara. Nevertheless, human expansion and impact has been much greater. Thus, natural regeneration and greening is generally lower in the Seno Plain as observed in Figure 5a,b. However, trends of GIMMS3g and GEOV1 FAPAR show different directions of change with a slightly positive trend in GEOV1 and a negative trend in GIMMS3g data. As most clearing of the dense bushland ended prior to the start of the time series, a positive trend is expected here as supported by several studies reporting large scale plantings, regeneration after droughts and an overall increase of tree cover in the last decade $[8,31,48]$.

\subsubsection{Linguère (Sahel of Senegal)}

Depending on soil, morphology, land-cover, human impact and drought resilience, areas react differently to rainfall changes, causing different magnitudes of trends (see Figure 5c,d). As rainfall is increasing over the past years (see Figure 3b), negative trends are almost not observed in both time series products. Clear differences in changes between the lateritic eastern and the sandy western areas exist. Droughts and dry years in the 1980s but also 1990s caused considerable damage to trees and shrubs on shallow lateritic soils in the east, visible in the temporal profiles of Figure $6 \mathrm{c}, \mathrm{f}$. The sandy soils in the west have a larger water storage capacity helping to temper the effects of droughts [2]. This can also be seen in the profiles of Figure 6d,e. Regeneration and therefore trends are thus much higher on lateritic soils (Figure 5c,d).

Despite the overall regeneration, the GIMMS3g FAPAR trend map shows that areas of less positive trends exist in the eastern region (see Figure 5d). GEOV1 FAPAR has a clearer spatial pattern than GIMMS3g, better differentiating between deforested and densely vegetated zones east of Linguère (Figure 5c). Thus the spatial pattern between the GIMMS3g and GEOV1 products is similar, but still critical disagreements are found at local scale.

Two oppositional test sites were chosen, one with an obvious positive woody vegetation trend (C3L5), and one with a large share of degraded land $(\mathrm{Ldeg})$. The temporal profiles in Figure $6 \mathrm{f}$ confirm that since 1982 the trend at $\mathrm{Ldeg}$ is slightly positive due to small forested depressions which react to increasing rainfall. The monitored area is small (around $5 \times 5 \mathrm{~km}$ ) and surrounded by dense bushland in the east and peanut fields in the north and west. The RapidEye image in Figure 1f shows that an $8 \mathrm{~km}$ grid is incapable of capturing this area correctly. In a pixel of $8 \mathrm{~km}$ spatial resolution the degraded area is mixed with adjacent land cover which explains the positive pattern around Ldeg in 
Figure 5d (GIMMS3g). Site visits showed that site Ldeg is an example for a degraded area where woody coverage is now only found in small clayey depressions. In the year 1965 the area was still covered by dense bushland [8] but nowadays most of the shallow soil is washed away and woody and herbaceous vegetation is very scarce here (see Figure 1f). Along with the unfavorable morphopedological characteristics and the proximity to several larger villages (e.g., Kol Kol, Kadji, Dodji), excessive browsing, cutting of living trees and livestock grazing are responsible for this development.

On the contrary, C3L5 has a positive trend (Figure 6c), caused by a denser woody vegetation. GIMMS3g does not capture this area correctly, as it is merged with a degraded area south of Barkedji, which is spatially overestimated in GIMMS3g. Information gathered in interviews confirm that tree mortality was high during the droughts in the 1980s and 1990s, also seen in Figure 6c. Additionally, the proximity to the national road makes this site vulnerable to the exploitation of woody products and thus this site was reported as degraded with a massive reduction in tree cover in the 1990s [37]. However, temporal profiles in Figure $6 \mathrm{c}$ and site visits (Figure 1c) reveal a dense woody vegetation and positive trend for the past decade.

\subsection{Validation and Interpretation of Trends by Ground Observations}

\subsubsection{Validation and Interpretation by Biomass Data}

CSE biomass data at C3L5 provides evidence of increasing leaf biomass between 1987 and 2010 (see Figure 7a) and thus proves that the GEOV1 trend (Figure 5c) and temporal profile (Figure 6c) are realistic. Inter-annual variability is very high, but after low values in the 1990s, leaf production is increasing rapidly (see Table 2), especially in the past decade, and corresponds well with integrated GEOV1 FAPAR (Figure 7a and Table 2). This phenomenon can not only be observed at the ferruginous test site $C 3 L 5$ but also at the sandy sites $C 2 L 5$ (Figure 7b) and C2L4 (Figure 7c) with significant leaf biomass increases. Again, this can be confirmed by GEOV1 FAPAR with similar increases at $C 2 L 5$ and C2L4 (Table 2). Since leaf biomass of woody species has almost doubled at our test sites, this is a clear sign of regeneration after an extraordinary dry period and its related consequences, beginning in the 1970s until the late 1990s (see Figure 7 and Table 2).

In contrast to the steep positive trend of the woody layer, a significant trend cannot be detected regarding the herbaceous biomass at all three test sites (see Figure 7a-c). Instead, major inter-annual fluctuations are observed, with a negative tendency at all three sites (see Table 2). This is obscured by the woody layer, which causes an overall positive trend. This is particularly true for $C 3 L 5$, with a strong positive trend in total biomass and FAPAR, but an insignificant negative trend in herbaceous biomass, in spite of increasing rainfall (see Figure $7 \mathrm{a}$ and Table 2). This is explained by soil erosion caused by water and livestock, leading to a spreading of bare soil at this site. Currently, it only affects the herbaceous layer. This phenomenon is hidden in our time series by a dense woody canopy cover and is an example for erosion and degradation obscured by greening. At the sandy test sites $C 2 L 5$ and $C 2 L A$, the negative trends in herbaceous biomass are mainly caused by extraordinary high values at the end of the 1980s (Figure 7b,c). Those herbaceous biomass peaks often occur after drought years and are caused by (1) the absence of livestock after severe drought years and the subsequent accumulation of biomass; 
(2) fertilization by dead-wood and (3) accumulation of seeds. Moreover, a change in the herbaceous species composition could be responsible for inter-annual biomass fluctuations [42].

Figure 7. Anomalies of CSE biomass at monitoring sites C3L5 (a);C2L5 (b) and C2L4 (c) and integrated GEOV1 FAPAR from 1987 to 2010. Note that biomass data is not available for each year. The plots give evidence of important conclusions: (1) large inter-annual discrepancies between biomass and FAPAR are not an exception; (2) the leaf biomass shows a strongly positive trend at all three sites and thus supports the FAPAR trend. Most leaf biomass and FAPAR anomalies before 2000 are negative, whereas they are mostly positive after 2000. This is an obvious sign for drought recovery; (3) No clear trends can be observed concerning the herbaceous biomass. Rather degradation is observed, especially at $C 3 L 5$, as it does not increase with rainfall.
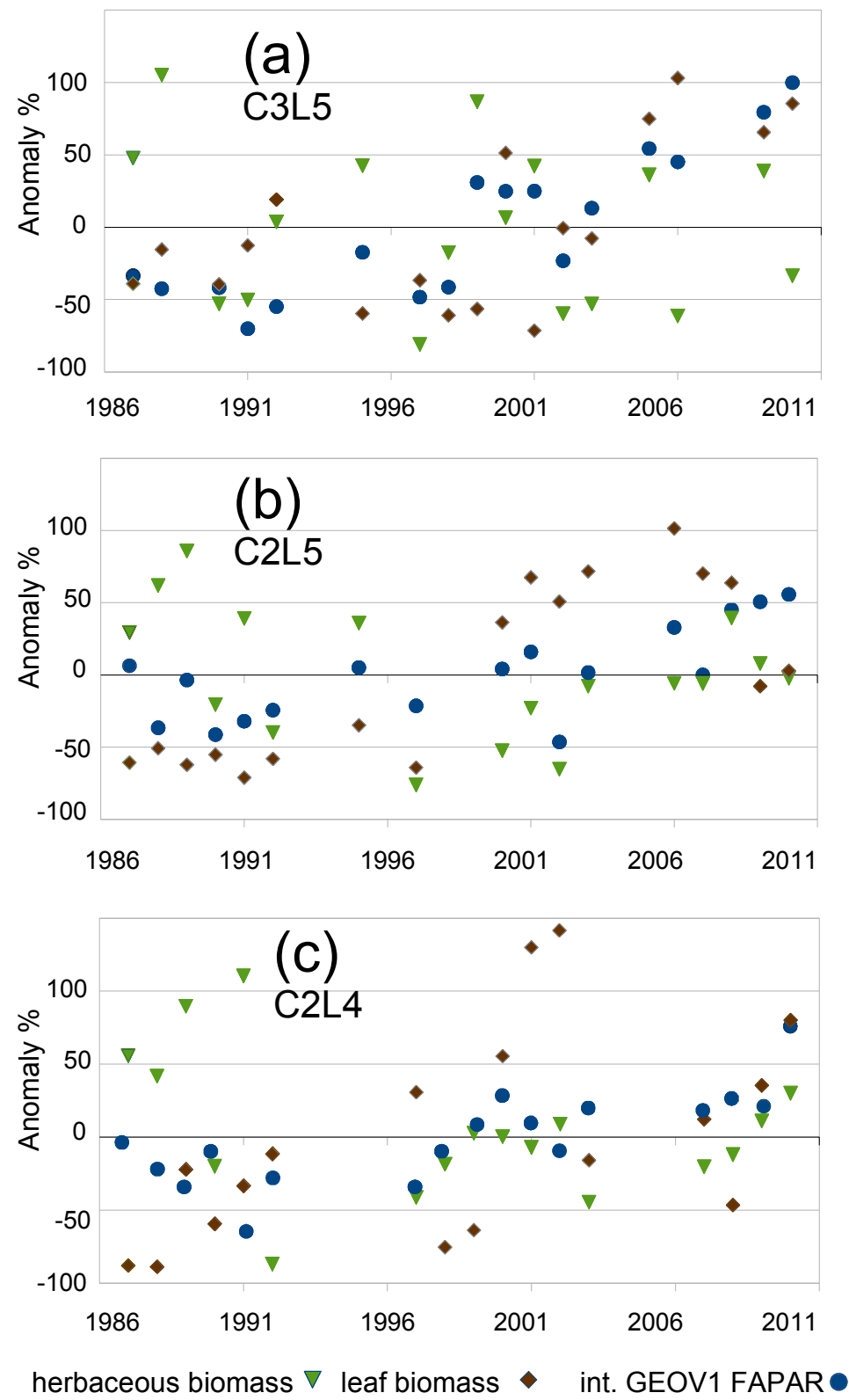
Table 2. The first four rows show vegetation change derived from linear regression for sites around Linguère (Senegal) for the period 1987-2010. ** = significant at 95\%; * = significant at $90 \%$ confidence level. Units are FAPAR and DM kg/ha. The change is calculated as the slope of annual values and multiplied by the number of years. It is further divided by the long-term mean to derive change in percent, shown in brackets. Note that a relationship between GEOV1 FAPAR and biomass trends is present and that FAPAR change increases with mean leaf biomass present.

\begin{tabular}{lllll}
\hline & C3L5 & C2L5 & C2L4 & Ldeg \\
\hline GEOV1 FAPAR change & $+0.22[104 \%]^{* *}$ & $+0.12[55 \%]^{* *}$ & $+0.11[38 \%]^{* *}$ & $+0.09[8 \%]^{* *}$ \\
GIMMS3g FAPAR change & $+0.011[7 \%]$ & $+0.012[3 \%]$ & $+0.012[4 \%]^{* *}$ & $+0.017[10 \%]^{*}$ \\
total biomass change & $+1025[59 \%]^{*}$ & $+149[10 \%]$ & $+140[13 \%]$ & \\
leaf biomass change & $+1172[93 \%]^{* *}$ & $+462[101 \%] * *$ & $+174[78 \%]^{*}$ & \\
herb. biomass change & $-147[-30 \%]$ & $-313[-28 \%]$ & $-34[-4 \%]$ & \\
mean leaf biomass & 1254 & 457 & 222 & \\
mean herb. biomass & 485 & 1085 & 865 & \\
\hline
\end{tabular}

By correlating integrated FAPAR with the total biomass for the monitoring sites $C 3 L 5, C 2 L 5$ and $C 2 L 4$, a highly significant relationship $(p \leq 0.01)$ for both FAPAR products (Figure 8 ) is obtained. For these sites, GEOV1 proves to be somewhat more reliable (Figure 8a; $\mathrm{R}^{2}=0.34$ ) than GIMMS3g (Figure $8 \mathrm{~b} ; \mathrm{R}^{2}=0.19$ ). However, even if a relationship between both FAPAR products and above-ground biomass observations is given, neither GEOV1 nor GIMMS3g prove to be robust proxies for biomass estimation in this area.

Figure 8. Scatterplots between ground based biomass (sites C3L5,C2L5,C2LA) and GEOV1(a)/GIMMS3g (b) pixel values obtained over the monitoring sites from 1987 to 2010. The relationships are not strong, but highly significant $(p \leq 0.01)$. Inter-annual discrepancies between observed biomass and satellite derived FAPAR are high, thus neither GEOV1 nor GIMMS3g FAPAR are robust proxies for biomass estimation.
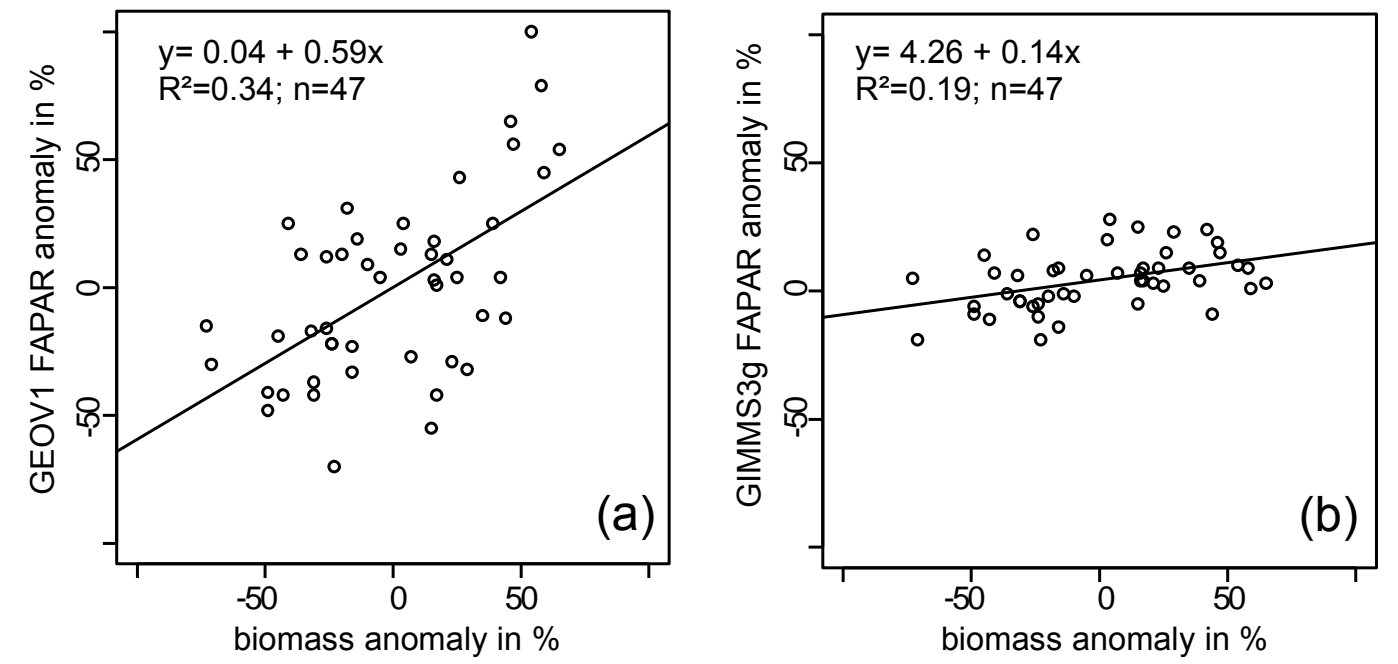


\subsubsection{Validation and Interpretation by Rainfall Data}

In the period 1982-2010, rainfall around Bandiagara shows a considerable increase which is significant at the $99 \%$ confidence level $(+281 \mathrm{~mm} ; 54 \% ; p \leq 0.01)$. According to Figure 9a,b, a relationship between annual rainfall and annual FAPAR exists over the entire Malian study area, explaining 58\% (GEOV1) and 30\% (GIMMS3g) of the variability. This is confirmed by the second study area around Linguère, where rainfall increased by $+142 \mathrm{~mm}(34 \% ; p \leq 0.1)$ over the same time period with $38 \%$ (GEOV1) and 48\% (GIMMS3g) of annual FAPAR anomalies being explained by annual rainfall fluctuations (Figure 9c,d respectively). These numbers give evidence that at regional scale precipitation explains much of the FAPAR variations.

Figure 9. Scatterplots showing relationships between annual rainfall (GPCC) and annual FAPAR anomalies averaged over the study areas around Bandiagara $(\mathbf{a}, \mathbf{b})$ and Linguère $(\mathbf{c}, \mathbf{d})$ for the period 1982-2010 (29 years).
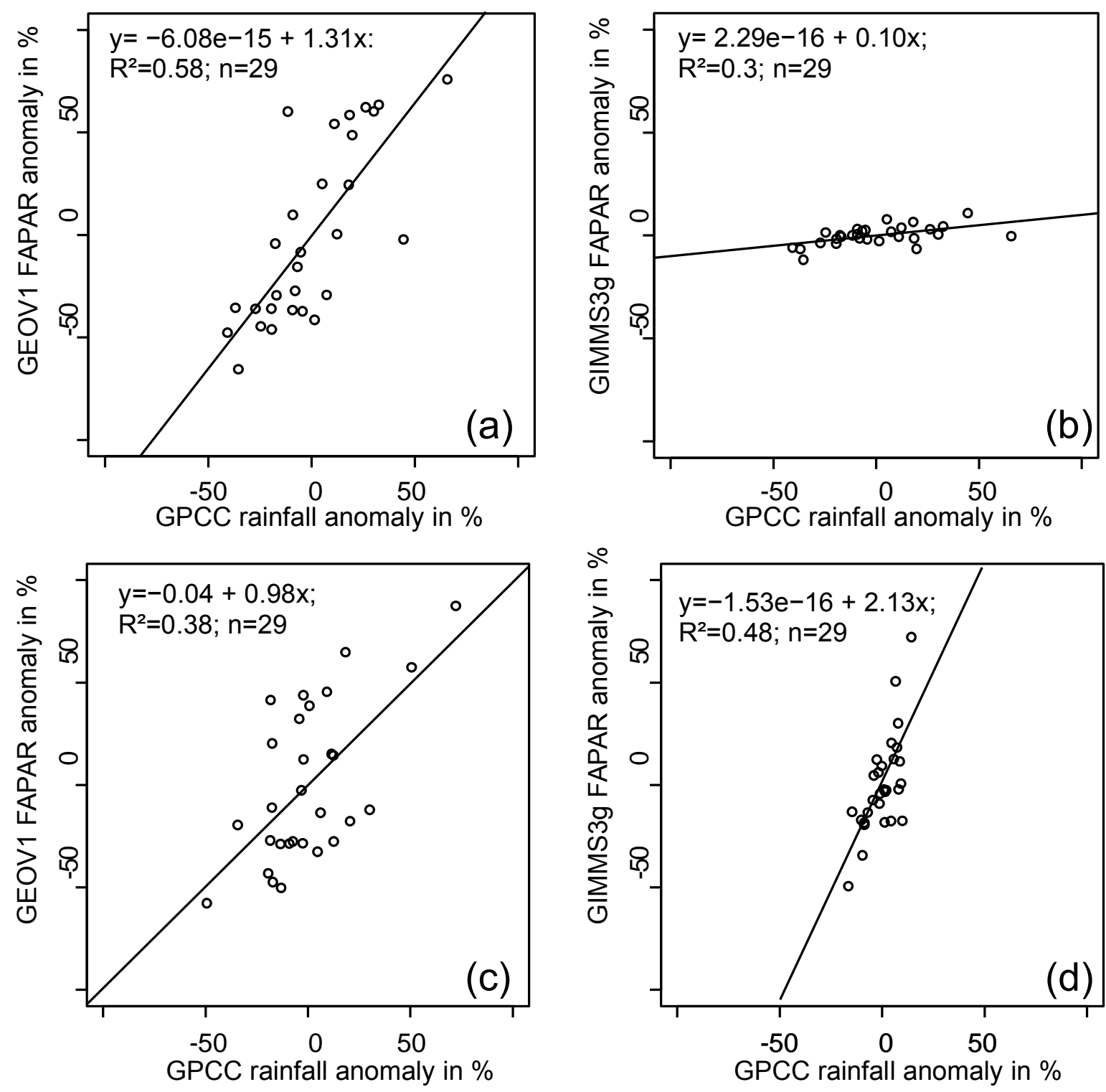
Correlating yearly CSE biomass $v s$. annual precipitation anomalies (1987-2010) verifies that rainfall is a causative factor for local vegetation change and variations $\left(\mathrm{R}^{2}=0.22 ; p \leq 0.01\right)$ at the sites $C 3 L 5$, $C 2 L 5$ and C2L4. Exactly the same result is obtained when correlating integrated GEOV1 FAPAR pixel values from the same sites against annual precipitation $\left(\mathrm{R}^{2}=0.22 ; p \leq 0.01\right)$, confirming the weak but highly significant relation. The weak correlation can be partly explained by local rainfall variations and the distance to the weather station. Moreover, Diouf \& Lambin [37] state that locally the response to rainfall is controlled by soil type, terrain, presence of plant seeds, variations in rain-use efficiency, species composition, the intra-annual distribution of rainfall as well as land-use practices. If the three biomass monitoring sites are averaged, the correlation is much stronger $\left(\mathrm{R}^{2}=0.55\right.$; $p \leq 0.01)$.

\section{Discussion}

The spatial pattern of trend analysis of GEOV1 and GIMMS3g FAPAR shows significant discrepancies in our Sahelian study areas. Initially it is not clear if trends realistically reflect patterns on the ground or are caused/accentuated by sensor-, processing- or scale issues. A combination of good data-sources, ground-truthing and local knowledge of the area are important factors that facilitate a sound interpretation and explanation of satellite derived trend maps.

Annual rainfall has significantly increased over the studied time period in both study areas, following the overall upward trend of Sahelian rainfall $[49,50]$. At a regional scale, this explains large parts of the observed positive vegetation trends [43] in the entire Sahel [9,27]. However, at a local scale, numerous variations exist, forming a heterogeneous pattern of vegetation trends [8]. A higher resolution clearly improves the capability to assess these discrepancies.

Our results show that the spatial pattern seen in satellite trend maps show regional differences that can partly be explained by soil and land-cover differences [9,51]. The sandy Seno Plain in Mali can be distinguished from the rocky Dogon Plateau. The same applies for the ferrugieous and the sandy Ferlo in Senegal (see Figure 5). Considering our Senegalese case studies, most of the positive trends are caused by leaf biomass, which has almost doubled at the three monitoring sites $(C 3 L 5, C 2 L 5$ and C2L4) since 1987. Local trend variations, i.e., areas of non-change or only weak change, are mostly caused by deforested and degraded areas. The droughts in the 1970s and 1980s caused considerable harm to trees. Additionally, people increasingly cut living trees in times of droughts as an alternative source for income and fodder. Trees and shrubs on sandy soils withstood the stress much better than those on shallow lateritic soils [2]. Although recovery of trees and shrubs from droughts is obvious in the biomass observations in Figure 9, Brandt et al. [8] state that strict laws, farmer managed protection, reforestation programs and the dispersion of robust species (especially Balanites aegyptiaca and Acacia raddiana) contribute to a large scale greening and increase in leaf biomass in both study areas in Mali and Senegal.

Our examples further demonstrate that both greening and degradation are present at a local scale in the West African Sahel, supporting the findings of Dardel et al. [9], Spiekermann [30], Nutini et al. [52] and Martinez et al. [12]. Neither greening nor desertification can be generalized. Our study detected degraded areas not following the greening trend, which is invoked by rainfall increases. However, neither 
is degradation irreversible, nor is greening an always positive phenomenon. In Mali, farmers were observed using traditional methods like stonewalls or holes with manure to recapture degraded soils near Fiko. Tree planting programs and farmer managed agro-forestry were observed all over the study areas in Mali and Senegal, confirming reports by Allen [48] and Reij et al. [53]. In addition, greening can mask degradation, as in both regions a remarkable species impoverishment was detected despite positive woody vegetation trends [8], a fact that coincides with other Sahelian studies [7,54]. In addition, areas seriously affected by soil erosion and spreading of bare soils can be concealed behind a greening trend caused by the woody layer (see C3L5).

The moderate correlation and major inter-annual discrepancies between biomass and satellite derived greenness data (Figures 7 and 8) confirm the findings of Diouf \& Lambin [37] and Diallo et al. [40]. As this study uses only three monitoring sites, the obtained relationships are weaker (see Figure 8a,b). Furthermore, the spatial resolution is much coarser (about $5 \mathrm{~km}$ compared to $1.1 \mathrm{~km}$ ). However, the biomass data at the observed sites gives clear evidence that the direction, the spatial discrepancies as well as the magnitude of FAPAR trend maps are largely realistic in this area. It further shows that woody vegetation is the main driver of positive FAPAR trends seen in Figure 5.

Although the two data products show good spatial consistency at an annual and regional scale (see Figure 2), the local pattern and magnitude of trends strongly differs. Degrading GEOV1 to $8 \mathrm{~km}$ resolution (results not shown for brevity) reduces the details but keeps the spatial pattern with apparent differences to GIMMS3g trend maps. Both datasets are created by sampled $1.1 \mathrm{~km}$ AVHRR data which are resampled to a $8 \mathrm{~km}(5 \mathrm{~km})$ grid cell by selecting subsets, while omitting other subsets [13]. The whole processing line of the FAPAR data causes significant variations and the choice of the dataset may have significant effects on the results [33,55-57]. In GEOV1 FAPAR data, the values of the VGT period are sometimes higher in densely vegetated areas than the AVHRR period, causing trends to be overestimated. On the contrary, trends in GIMMS3g FAPAR are too weak and significantly underestimated. The base levels of GIMMS3g FAPAR are much higher than those of GEOV1 FAPAR. Our comparison with ground data showed that the reality lies in between the two products, but closer to GEOV1. These differences in the processing line may influence the magnitude of trend analysis and bias the significance test, but the spatial pattern of GEOV1 trends shows agreement with ground observations (Table 3).

Table 3. This table presents significant $(p \leq 0.01)$ changes (see Table 2 for methodology) for the period 1987-2010. $++50 \%-105 \%,+10 \%-50 \%$, o $<10 \%$.

\begin{tabular}{clcllc}
\hline Sites & GEOV1 & GIMMS3g & Leaf Biomass & Observations & Rainfall \\
\hline MALdeg & o & not significant & NA & active degradation & ++ \\
MALpos & ++ & o & NA & new plantations & ++ \\
$C 3 L 5$ & ++ & not significant & ++ & drought recovery & + \\
$C 2 L 5$ & ++ & not significant & ++ & drought recovery & + \\
$C 2 L 4$ & + & o & ++ & drought recovery & + \\
Ldeg & o & + & NA & degradation & + \\
\hline
\end{tabular}




\section{Conclusions}

This study focused on the local vegetation trends in drylands of Western Africa (Sahel of Mali and Senegal) over the 1982-2010 period. Two long-term satellite datasets of Fraction of Absorbed Photosynthetically Active Radiation (FAPAR) derived from Advanced Very High Resolution Radiometer (AVHRR) data were considered: Geoland Version 1 (GEOV1) and the third generation Global Inventory Modeling and Mapping Studies (GIMMS3g). Biomass ground measurements and rainfall data supported a quantitative validation of detected trends in satellite products. Auxiliary information and expert knowledge of the study areas allowed a qualitative validation and interpretation of the local observed trends.

Our results show that the choice of the dataset has significant impact on the results. The study seems to indicate that, compared to GIMMS3g, the spatial pattern of GEOV1 trends show a better agreement with ground data, rainfall pattern, land-cover, land management of the two study areas in the Sahel of Mali and Senegal. The differences in the processing lines (input reflectances and retrieval algorithms) seem to play a role in the observed differences rather beside the differences in their spatial resolution. Note however that our conclusions on the accuracy of GEOV1 and GIMMS3g time series for trend detection analysis are limited to the study areas. An extensive validation and comparison of both datasets at global scale should be addressed in a forthcoming study. This study shows the potential of GEOV1 for local trend detection. However, some inconsistencies have been detected in the GEOV1 dataset and are being to be corrected. Correction will be achieved through a second version of Geoland Version 2 (GEOV2) products from VEGETATION (VGT) and AVHRR sensors which is expected to contribute to global climate monitoring and earth science modelling applications.

The inter-annual correlation between FAPAR and annual rainfall is significant over the study areas, explaining around $50 \%$ of the variability in vegetation changes. Spatial discrepancies are mainly caused by land- and tree-cover, which are controlled by soil, human and drought resilience. As precipitation in the Sahel was very low when the time series started in 1982 and gradually increased, a positive greening trend is mostly observed in the study area. However, deforested and degraded areas clearly stand out in GEOV1 trend maps while they are hardly visible in GIMMS3g. The positive trends of the three case study sites in Senegal (C3L5,C2L5 and C2L4) are caused by the woody layer recovering from droughts/dry periods and its consequences.

These local patterns have shown that both greening and degradation are present in the Sahel of Mali and Senegal, but also greening can hide degradation. Neither the re-greening nor the desertification paradigm can be generalized as both are present at a local level.

\section{Acknowledgments}

The authors thank the colleagues from the CSE, especially Moussa Sall for a great collaboration and for collecting and sharing biomass data for such a long time period. The research is part of the BMBF funded project micle, which aims to find linkages between climate, environment and migration. We would like to thank all the guides, drivers and translators in the field (mainly Mohammed Lecor and Yaya Koetioumbe) as well as the project colleagues, especially Clemens Romankiewicz, Raphael Spiekermann and Tobias Grau. Further thank goes to Z. Zhu for providing GIMMS3g data, Geoland2 
for GEOV1 data and the DLR/RESA for RapidEye imagery. Aleixandre Verger is recipient of a Juan de la Cierva postdoctoral fellowship from the Spanish Ministry of Science and Innovation. The authors thank the anonymous referees for significantly improving the manuscript. This publication was funded by the German Research Foundation (DFG) and the University of Bayreuth in the funding programme Open Access Publishing.

\section{Author Contributions}

The conception of the research approach and development of the methods was done by M. Brandt, A. Verger and C. Samimi. The data was collected and prepared by A. Diouf (CSE), F. Baret, A. Verger (both Geoland2) and M. Brandt. The research was conducted by M. Brandt. Analysis and interpretation was done by M. Brandt and A. Verger and discussed with all authors. The manuscript was written by M. Brandt and A. Verger with contributions from all authors.

\section{Conflicts of Interest}

The authors declare no conflicts of interest.

\section{References}

1. Ali, A.; Lebel, T. The Sahelian standardized rainfall index revisited. Int. J. Climatol. 2009, 29, 1705-1714.

2. Tappan, G.; Sall, M.; Wood, E.; Cushing, M. Ecoregions and land cover trends in Senegal. J. Arid Environ. 2004, 59, 427-462.

3. Oldeman, L.R.; Hakkeling, R.T.A.; Sombroek, W.G. World Map of the Status of HumanInduced Soil Degradation: An Explanatory Note; ISRIC: Wageningen, The Netherlands, 1990. Avaliable online: http://www.isric.org/isric/webdocs/docs/ExplanNote.pdf (accessed on 15 December 2013).

4. Herrmann, S.M.; Anyamba, A.; Tucker, C.J. Recent trends in vegetation dynamics in the African Sahel and their relationship to climate. Glob. Environ. Chang. 2005, 15, 394-404.

5. Hutchinson, C.; Herrmann, S.; Maukonen, T.; Weber, J. Introduction: The "Greening" of the Sahel. J. Arid Environ. 2005, 63, 535-537.

6. Olsson, L.; Eklundh, L.; Ardo, J. A recent greening of the Saheltrends, patterns and potential causes. J. Arid Environ. 2005, 63, 556-566.

7. Herrmann, S.; Tappan, G. Vegetation impoverishment despite greening: A case study from central Senegal. J. Arid Environ. 2013, 90, 55-66.

8. Brandt, M.; Romankiewicz, C.; Spiekermann, R.; Samimi, C. Environmental change in time series-An interdisciplinary study in the Sahel of Mali and Senegal. J. Arid Environ. 2014, in press.

9. Dardel, C.; Kergoat, L.; Hiernaux, P.; Mougin, E.; Grippa, M.; Tucker, C. Re-greening Sahel: 30 years of remote sensing data and field observations (Mali, Niger). Remote Sens. Environ. 2014, 140, 350-364. 
10. Fensholt, R.; Rasmussen, K.; Nielsen, T.T.; Mbow, C. Evaluation of earth observation based long term vegetation trendsIntercomparing NDVI time series trend analysis consistency of Sahel from AVHRR GIMMS, Terra MODIS and SPOT VGT data. Remote Sens. Environ. 2009, $113,1886-1898$.

11. Fensholt, R.; Proud, S.R. Evaluation of earth observation based global long term vegetation trends Comparing GIMMS and MODIS global NDVI time series. Remote Sens. Environ. 2012, $119,131-147$.

12. Martinez, B.; Gilabert, M.; Garca-Haro, F.; Faye, A.; Meli, J. Characterizing land condition variability in Ferlo, Senegal (2001-2009) using multi-temporal 1-km Apparent Green Cover (AGC) SPOT Vegetation data. Glob. Planet. Chang. 2011, 76, 152-165.

13. Fensholt, R.; Sandholt, I.; Rasmussen, M.S. Evaluation of MODIS LAI, fAPAR and the relation between fAPAR and NDVI in a semi-arid environment using in situ measurements. Remote Sens. Environ. 2004, 91, 490-507.

14. Wagenseil, H.; Samimi, C. Assessing spatio-Temporal variations in plant phenology using Fourier analysis on NDVI time series: Results from a dry savannah environment in Namibia. Int. J. Remote Sens. 2006, 27, 3455-3471.

15. Wessels, K.J.; Prince, S.D.; Frost, P.E.; van Zyl, D. Assessing the effects of human-induced land degradation in the former homelands of northern South Africa with a $1 \mathrm{~km}$ AVHRR NDVI time-series. Remote Sens. Environ. 2004, 91, 47-67.

16. Dybkjaer, G.; Nielsen, T.T.; Rasmussen, K.; Schultz-Rasmussen, M.; Lars Boye, H.; Tour, A. Documentation and evaluation of the CSE NOAA AVHRR data set. Geografisk Tidsskrift. 2003, $103,125-135$.

17. Tucker, C.; Pinzon, J.; Brown, M.; Slayback, D.; Pak, E.; Mahoney, R.; Vermote, E.; El Saleous, N. An extended AVHRR 8-km NDVI dataset compatible with MODIS and SPOT vegetation NDVI data. Int. J. Remote Sens. 2005, 26, 4485-4498.

18. Bégué, A.; Vintrou, E.; Ruelland, D.; Claden, M.; Dessay, N. Can a 25-year trend in Soudano-Sahelian vegetation dynamics be interpreted in terms of land use change? A remote sensing approach. Glob. Environ. Chang. 2011, 21, 413-420.

19. Heumann, B.W.; Seaquist, J.W.; Eklundh, L.; Jonsson, P. AVHRR derived phenological change in the Sahel and Soudan, Africa, 1982-2005. Remote Sens. Environ. 2007, 108, 385-392.

20. Anyamba, A.; Tucker, C. Analysis of Sahelian vegetation dynamics using NOAA-AVHRR NDVI data from 1981-2003. J. Arid Environ. 2005, 63, 596-614.

21. Zhu, Z.; Bi, J.; Pan, Y.; Ganguly, S.; Anav, A.; Xu, L.; Samanta, A.; Piao, S.; Nemani, R.; Myneni, R. Global data sets of vegetation Leaf Area Index (LAI)3g and Fraction of Photosynthetically Active Radiation (FPAR)3g ferived from global Inventory Modeling and Mapping Studies (GIMMS) Normalized Difference Vegetation Index (NDVI3g) for the period 1981 to 2011. Remote Sens. 2013, 5, 927-948.

22. Baret, F.; Weiss, M.; Lacaze, R.; Camacho, F.; Makhmara, H.; Pacholcyzk, P.; Smets, B. GEOV1: LAI and FAPAR essential climate variables and FCOVER global time series capitalizing over existing products. Part1: Principles of development and production. Remote Sens. Environ. 2013, 137, 299-309. 
23. Verger, A.; Baret, F.; Weiss, M.; Lacaze, R.; Makhmara, H.; Vermote, E. Long Term Consistent Global GEOV1 AVHRR Biophysical Products. In Proceedings of the 1st EARSeL Workshop on Temporal Analysis of Satellite Images, Mykonos, Greece, 23-25 May 2012; pp. 28-33.

24. Vrieling, A.; de Leeuw, J.; Said, M.Y. Length of growing period over Africa: Variability and trends from 30 years of NDVI time series. Remote Sens. 2013, 5, 982-1000.

25. De Jong, R.; Verbesselt, J.; Zeileis, A.; Schaepman, M.E. Shifts in global vegetation activity trends. Remote Sens. 2013, 5, 1117-1133.

26. Cook, B.I.; Pau, S. Aglobal assessment of long-term greening and browning trends in pasture lands using the GIMMS LAI3g dataset. Remote Sens. 2013, 5, 2492-2512.

27. Fensholt, R.; Rasmussen, K.; Kaspersen, P.; Huber, S.; Horion, S.; Swinnen, E. Assessing land degradation/recovery in the african sahel from long-term earth observation based primary productivity and precipitation relationships. Remote Sens. 2013, 5, 664-686.

28. Baret, F.; Weiss, M.; Verger, A.; Kandasamy, S. BioPar Methods Compendium-LAI, FAPAR and FCOVER from LTDR AVHRR Series; Technical Report; INRA-EMMAH: Avignon, France, 2011.

29. Myneni, R.B.; Williams, D.L. On the relationship between FAPAR and NDVI. Remote Sens. Environ. 1994, 49, 200-211.

30. Spiekermann, R.; Brandt, M.; Samimi, C. Using High Resolution Imagery to Detect Woody Vegetation and Land-Cover Change over 50 Years in the Sahel of Mali. In Proceedings of the EGU General Assembly Conference Abstracts, Vienna, Austria, 7-12 April 2013; Volume 15, p. 11937.

31. Spiekermann, R. Change of Woody Vegetation and Land Cover Using High Resolution Images on the Dogon Plateau and Sno Plains (Mali). M.Sc. Thesis, University of Vienna, Vienna, Austria, 2013.

32. RapidEye. Satellite Imagery Product Specifications; 2013. Available online: http://blackbridge.com/rapideye/upload/RE_Product_Specifications_ENG.pdf (accessed on 25 February 2014).

33. Weiss, M.; Baret, F.; Garrigues, S.; Lacaze, R. LAI and fAPAR CYCLOPES global products derived from VEGETATION. Part 2: Validation and comparison with MODIS collection 4 products. Remote Sens. Environ. 2007, 110, 317-331.

34. Verger, A.; Baret, F.; Weiss, M. Performances of neural networks for deriving LAI estimates from existing CYCLOPES and MODIS products. Remote Sens. Environ. 2008, 112, 2789-2803.

35. Cleveland, R.B.; Cleveland, W.S.; McRae, J.E.; Terpenning, I. STL: A seasonal-trend decomposition procedure based on loess. J. Off. Stat. 1990, 6, 3-73.

36. Roderick, M.L.; Noble, I.R.; Cridland, S.W. Estimating woody and herbaceous vegetation cover from time series satellite observations. Glob. Ecol. Biogeogr. 1999, 8, 501-508.

37. Diouf, A.; Lambin, E.F. Monitoring land-cover changes in semi-arid regions: Remote sensing data and field observations in the Ferlo, Senegal. J. Arid Environ. 2001, 48, 129-148.

38. Maydell, H.J.V. Trees and Shrubs of the Sahel: Their Characteristics and Uses; Verlag Josef Margraf: Weikersheim, Germany, 1990. 
39. Stocking, M.A.; Murnaghan, N. A Handbook for the Field Assessment of Land Degradation; Routledge: London, UK, 2001.

40. Diallo, O.; Diouf, A.; Hanan, N.P.; Ndiaye, A.; Prevost, Y. AVHRR monitoring of savanna primary production in Senegal, West Africa: 1987-1988. Int. J. Remote Sens. 1991, 12, 1259-1279.

41. Fensholt, R.; Sandholt, I.; Rasmussen, M.S.; Stisen, S.; Diouf, A. Evaluation of satellite based primary production modelling in the semi-arid Sahel. Remote Sens. Environ. 2006, 105, 173-188.

42. Mbow, C.; Fensholt, R.; Rasmussen, K.; Diop, D. Can vegetation productivity be derived from greenness in a semi-arid environment? Evidence from ground-based measurements. J. Arid Environ. 2013, 97, 56-65.

43. Hickler, T.; Eklundh, L.; Seaquist, J.; Smith, B.; Ard, J.; Olsson, L.; Sykes, M.; Sjstrm, M. Precipitation controls Sahel greening trend. Geophys. Res. Lett. 2005, 32, L21415.

44. Strommer, G.; Brandt, M.; Diongue-Niang, A.; Samimi, C. Analysis of Daily Rainfall of the Sahelian Weather-Station Linguere (Senegal)-Trends and its Impacts on the Local Population. In Proceedings of the EGU General Assembly Conference Abstracts, Vienna, Austria, 7-12 April 2013; Volume 15, p. 12716.

45. Schneider, U.; Becker, A.; Finger, P.; Meyer-Christoffer, A.; Ziese, M.; Rudolf, B. GPCC's new land surface precipitation climatology based on quality-controlled in situ data and its role in quantifying the global water cycle. Theor. Appl. Climatol. 2014, 115, 15-40.

46. Brandt, M.; Paeth, H.; Samimi, C. Vegetations veraenderungen in Westafrika-Spiegel von Klimawandel und Landnutzung. Geogr. Rundschau 2013, 65, 36-42.

47. FAO. Global Forest Resources Assessment 2010, Global Tables; Technical Report; FAO: Rome, Italy, 2010. Available online: http://foris.fao.org/static/data/ fra2010/FRA2010GlobaltablesEnJune29.xls (accessed on 23 October 2013.)

48. Allen, M. International Tree Foundation Narrative Report-MA295 Sahel ECO; Technical Report; Sahel ECO: Bamako, Mali, 2009.

49. Nicholson, S.E. The West African Sahel: A review of recent studies on the rainfall regime and its interannual variability. ISRN Meteorol. 2013, 2013, 1-32.

50. Giannini, A.; Salack, S.; Lodoun, T.; Ali, A.; Gaye, A.T.; Ndiaye, O. A unifying view of climate change in the Sahel linking intra-seasonal, interannual and longer time scales. Environ. Res. Lett. 2013, 8, doi:10.1088/1748-9326/8/2/0240100.

51. Bobée, C.; Ottlé, C.; Maignan, F.; de Noblet-Ducoudré, N.; Maugis, P.; Lézine, A.M.; Ndiaye, M. Analysis of vegetation seasonality in Sahelian environments using MODIS LAI, in association with land cover and rainfall. J. Arid Environ. 2012, 84, 38-50.

52. Nutini, F.; Boschetti, M.; Brivio, P.; Bocchi, S.; Antoninetti, M. Land-use and land-cover change detection in a semi-arid area of Niger using multi-temporal analysis of Landsat images. Int. J. Remote Sens. 2013, 34, 4769-4790.

53. Reij, C.; Tappan, G.; Smale, M. Agroenvironmental Transformation in the Sahel: Another Kind of "Green Revolution"; Technical Report; International Food Policy Research Institute: Washington, DC, USA, 2009. 
54. Gonzalez, P. Desertification and a shift of forest species in the West African Sahel. Clim. Res. 2001, 17, 217-228.

55. Pickett-Heaps, C.A.; Canadell, J.G.; Briggs, P.R.; Gobron, N.; Haverd, V.; Paget, M.J.; Pinty, B.; Raupach, M.R. Evaluation of six satellite-derived Fraction of Absorbed Photosynthetic Active Radiation (FAPAR) products across the Australian continent. Remote Sens. Environ. 2014, 140, 241-256.

56. Meroni, M.; Atzberger, C.; Vancutsem, C.; Gobron, N.; Baret, F.; Lacaze, R.; Eerens, H.; Leo, O. Evaluation ofagreement between space remote sensing SPOT-VEGETATION fAPAR time series. IEEE Trans. Geosci. Remote Sens. 2013, 51, 1951-1962.

57. McCallum, I.; Wagner, W.; Schmullius, C.; Shvidenko, A.; Obersteiner, M.; Fritz, S.; Nilsson, S. Comparison of four global FAPAR datasets over Northern Eurasia for the year 2000. Remote Sens. Environ. 2010, 114, 941-949.

(C) 2014 by the authors; licensee MDPI, Basel, Switzerland. This article is an open access article distributed under the terms and conditions of the Creative Commons Attribution license (http://creativecommons.org/licenses/by/3.0/). 